\title{
Simulation of parallel capacitance influence on the hydraulic system dynamics
}

\author{
Dýrr Filip ${ }^{1 *}$, Hružík Lumír ${ }^{1}$, Bureček Adam ${ }^{1}$ and Brzezina Petr $^{1}$ \\ ${ }^{1}$ VŠB - Technical University of Ostrava, Faculty of Mechanical Engineering, Department of Hydromechanics and Hydraulic Equipment, \\ 70833 Ostrava, Czech Republic
}

\begin{abstract}
This paper covers with experimental measurement and mathematical simulation of parallel capacitance influence on pressure response for non-stationary flow. The hydraulic circuit for measuring required quantities, which are necessary to determine of parallel capacitance influence on the hydraulic system dynamics. A part of hydraulic system is a long pipe, in which the parallel capacitance created by hydraulic hose is connected. A non-stationary flow is caused by fast closing of the seat valve, which is situated at the end of long pipe. Mathematical model is realized and verified in Matlab SimScape Fluids software for this hydraulic system.
\end{abstract}

\section{Introduction}

Rapid increase of pressure occurs during hydraulic shock, which causes unwanted effects such as vibrations, more severe straining of hydraulic parts and shorter lifespan of the whole system.

One of the options used to partly eliminate quickly emerging pressure peaks during hydraulic shock is to suitably place a part, which possesses hydraulic capacitance into the system. Hydraulic capacitance is an ability of a part to accumulate a part of hydraulic liquid in itself while being affected by pressure energy. Capacitance can also be created by an accumulator but also the hydraulic lines by itself.

Connected parallel capacitance makes it possible to absorb a part of the pressure energy during hydraulic shock. Hydraulic hose is chosen as the part for testing and it is connected as close as possible to the point of origin of hydraulic shock. The flexibility and inner diameter of the hose determines its capacitance. Flexibility of the hose is influenced by the number of steel braids. The fewer braids there are, the lesser is the resistance of the hose against deformation, therefore its capacitance is higher. The inner diameter and length decide the volume of the hose. A hose which has the same number of braids than another one but higher inner diameter has higher volume and is more flexible.

Another element which influences hydraulic capacitance is the hydraulic fluid used. Particularly the oil bulk modulus, which significantly influences the volume of undissolved air in the fluid $[1,2,3]$.

Hydraulic capacitance is given by the increase in effective stored fluid volume $V$ per change in pressure [4]:

$$
C=\frac{d V}{d p}
$$

where $d V$ is volume change and $d p$ is pressure change.
Pressure response with respect to time during hydraulic shock is also affected by hydraulic capacitance of connected hose, capacitance of pipeline and capacitance, which is created by fluid compressibility. Change of parallel capacitance's degree is done by different hoses, which are connected.

It can be assumed that the parallelly connected hydraulic capacitance created by hydraulic hose could have positive influence on the pressure peak during hydraulic shock. During supression of the pressure peak, a slight straining of all hydraulic parts, which are affected by the pressure wave caused by hydraulic shock, occurs.

\section{Description of experimental hydraulic circuit and measurement}

An experimental device is created in order to execute the hydraulic shock in a pipeline and to determine the influence of parallel capacitance. Parallel capacitance is formed by hose $\mathrm{H}$. Hose $\mathrm{H}$ is connected at the end of pipeline P right in front of seat valve SV. Hydraulic shock is caused by fast closing of the seat valve SV [5]. For this experiment, hoses of different inner diameter and number of steel braids were chosen. These parameters influence the capacitance of hose $\mathrm{H}$. The pressure sensor PS scans the pressure response in front of seat valve SV at the point of origin of the hydraulic shock. It also scans the flow rate of oil $Q$ through flow sensor FS and the temperature of the oil $t_{o}$ by temperature sensor TS. The data is being recorded by measuring device MS 5060+ Hydrotechnik.

\footnotetext{
$\overline{{ }^{*} \text { Corresponding author: filip.dyrr@vsb.cz }}$
} 
The scheme of the experimental device is in figure 1. The source of pressure energy is hydraulic pump HP. HP pump is protected against pressure peaks by check valve CV. Relief valve RV sets pressure $p_{R V}$. Oil supplied by the pump flows into a pipeline $\mathrm{P}$ with length $l=60 \mathrm{~m}$, inner diameter $d=12 \mathrm{~mm}$ and wall thickness $s=2 \mathrm{~mm}$. At the end of the pipeline $\mathrm{P}$ the oil flows through seat valve SV into flow sensor FS. From flow sensor FS the oil flows straight to tank T. Ball valve BV1 connects the parallel capacitance, ball valve BV2 is in the circuit for venting of hose $\mathrm{H}$ (see table 1$)$.

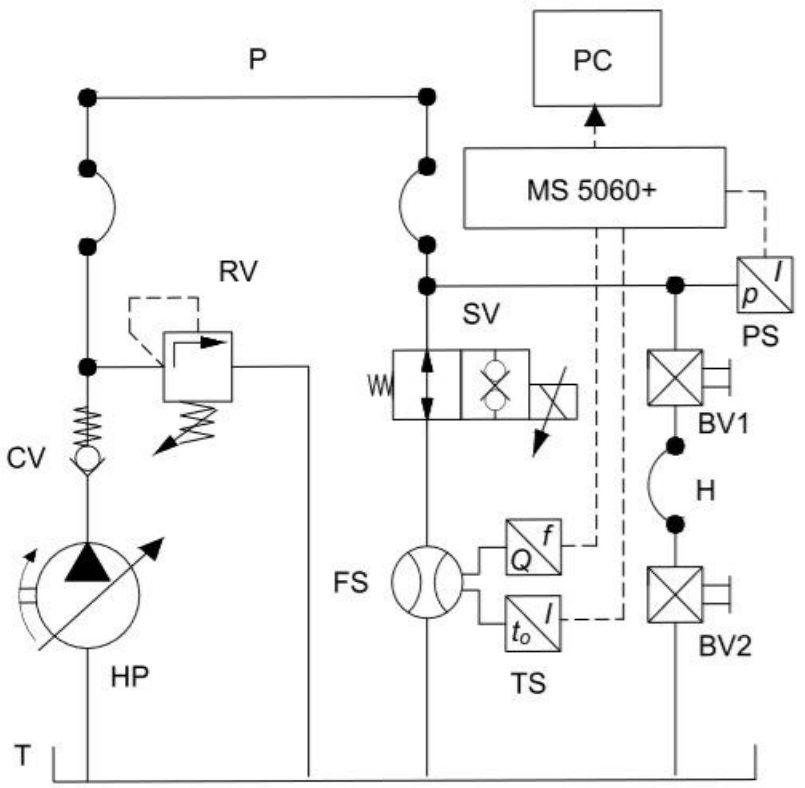

Fig. 1. Scheme of hydraulic circuit

Table 1. List of used hydraulic parts

\begin{tabular}{|c|c|}
\hline HP & Hydraulic Pump \\
\hline CV & Check Valve \\
\hline RV & Relief Valve \\
\hline P & Pipeline \\
\hline SV & Seat Valve \\
\hline FS & Flow Sensor \\
\hline T & Tank \\
\hline PS & Pressure Sensor \\
\hline H & Hose \\
\hline BV & Ball Valve \\
\hline
\end{tabular}

Flow rate through the hydraulic circuit is set to $Q=20 \mathrm{dm}^{3} \cdot \mathrm{min}^{-1}$. Pressure on relief valve $\mathrm{RV}$ is set to $p_{R V}=75$ bar. Subsequently, hydraulic shock is caused by fast closing of seat valve SV. After reaching the pressure $p_{R V}$, the oil flows straight into tank $\mathrm{T}$ through relief valve RV. For this action record of measuring is made.

During the measuring of pressure response without parallel capacitance, the ball valve BV1 is closed. Pressure response is measured without the influence of parallel capacitance of hose $H$. Subsequently, ball valve BV1 is open, connecting the capacitance of hose $\mathrm{H}$ to the circuit (see figure 2). Before measuring the pressure response with the influence of parallel capacitance, venting of hose $\mathrm{H}$ is done by opening ball valve BV2 and the fluid flows through hose $\mathrm{H}$ to tank $\mathrm{T}$.
After that, the measuring of pressure response with connected parallel capacitance is conducted. Same measuring procedure is repeated for other hoses with different parameters respectively. Measured data is processed using Hydrowin and Excel, in which graphs of pressure response during non-stationary flow are made.

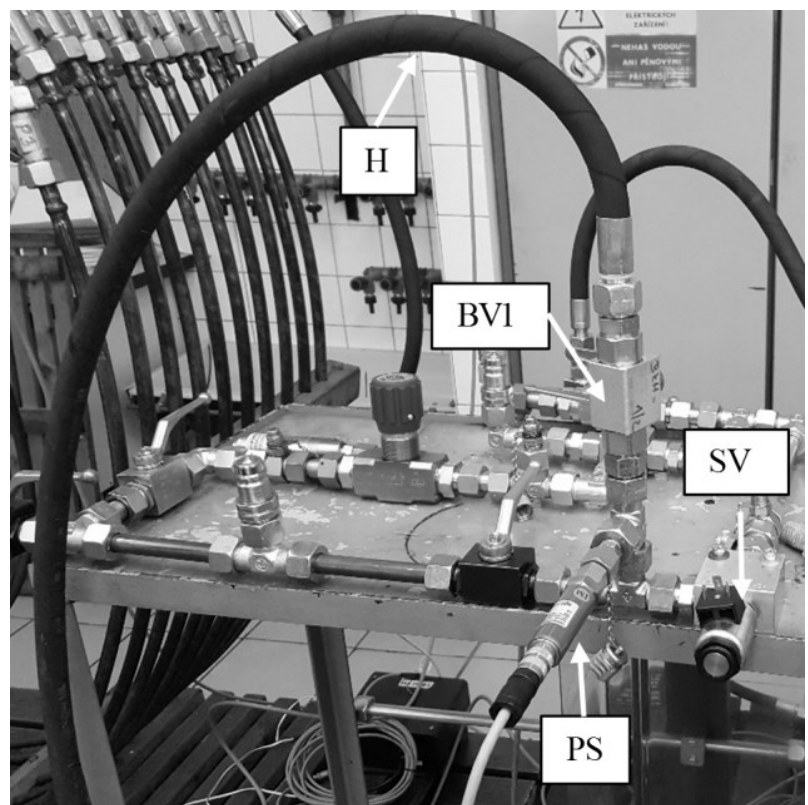

Fig. 2. Connected hydraulic hose

All hoses used for testing are of the same length. They differ in inner diameter and number of steel braids (see table 2). It can be assumed that a hose with lower number of steel braids shall have higher capacitance, if the inner diameter is the same. It can also be assumed that the hose with the same number of steel braids but higher inner diameter, will have higher capacitance. During a hydraulic shock a rapid increase of pressure peak occurs. When parallel capacitance is connected, the pressure peak should reach smaller values than without connected capacitance created by hydraulic hose.

Table 2. Parameters of used hydraulic hoses

\begin{tabular}{|c|c|c|c|}
\hline $\begin{array}{c}\text { Signification } \\
\text { of hose }\end{array}$ & $\begin{array}{c}\text { Inner } \\
\text { diameter }\end{array}$ & $\begin{array}{c}\text { Number } \\
\text { of steel } \\
\text { braids }\end{array}$ & Length \\
\hline$[-]$ & {$[\mathrm{mm}]$} & {$[-]$} & {$[\mathrm{mm}]$} \\
\hline 1 & 25 & $1 \mathrm{SN}$ & 2000 \\
\hline 2 & 25 & $2 \mathrm{SN}$ & 2000 \\
\hline 3 & 10 & $1 \mathrm{SN}$ & 2000 \\
\hline 4 & 10 & $2 \mathrm{SN}$ & 2000 \\
\hline
\end{tabular}

During the entire experiment the temperature was $t_{o}=48.5 \pm 0.5^{\circ} \mathrm{C}$. The hydraulic oil used reached kinematic viscosity of $v=31.9 \mathrm{~mm}^{2} \cdot \mathrm{s}^{-1}$ at given temperature. 


\section{Results of experimental measuring}

Figure 3 lists the time dependence of pressure $p$ during closing seat valve SV. Pressure $p$ is scanned by pressure sensor PS. Graph shows that the pressure peak is highest without connected parallel capacitance. After connecting hose 1 the highest supression of pressure peak occurs. Capacitance of this hose absorbed part of pressure energy which was created during hydraulic shock. Hose 2 has a similar pressure trend as hose 1 . However, the graph shows that because of the two steel braids, hose is tougher than hose 1 . Hose 3 also has decreased pressure peak. This hose has lower capacitance than hoses 1 and 2 and that is why the supression of the pressure peak is not as visible as with hoses 1 and 2 . The degree of pressure peak when hose 4 is connected is similar to the one where parallel capacitance is not connected. Hose 4 capacitance is not big enough to decrease the pressure peak. Graph shows that the inner diameter of the hose significantly affects its capacitance. It is also clear that a smaller number of steel braids increases the capacitance of hydraulic hose but is not as important as the inner diameter of the hose. This measuring confirms that parallelly connected capacitance leads to decreasing of pressure peak.

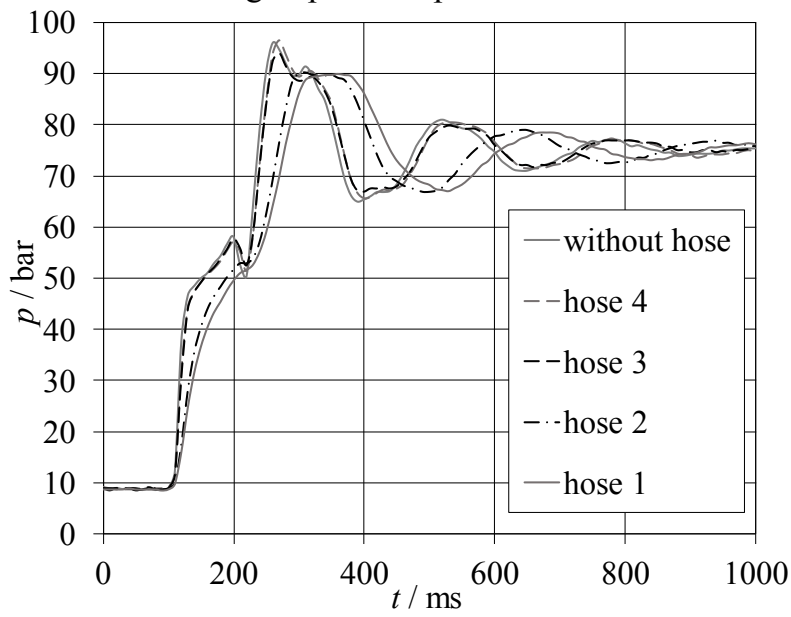

Fig. 3. Comparison of parallel capacitance influence

Table 3 allows you to see the measured data after connecting hoses of different capacitance. It also states the degree of set pressure $p_{R V}$, also pressure peaks and it shows data about how much the pressure peak exceeds pressure $p_{R V}$.

Table 3. Measured data

\begin{tabular}{|c|c|c|c|}
\hline $\begin{array}{l}\text { Signification } \\
\text { of hose }\end{array}$ & $\begin{array}{c}\text { Pressure } \\
p_{R V} \text { on } \\
\text { relief valve } \\
\mathrm{RV} \\
\end{array}$ & $\begin{array}{c}\text { Pressure } \\
\text { peak }\end{array}$ & $\begin{array}{l}\text { Pressure } \\
\text { overshoot }\end{array}$ \\
\hline$[-]$ & [bar] & [bar] & [bar] \\
\hline without hose & \multirow{5}{*}{75} & 96.5 & 21.5 \\
\hline hose 1 & & 90.4 & 15.4 \\
\hline hose 2 & & 90.6 & 15.6 \\
\hline hose 3 & & 94.6 & 19.6 \\
\hline hose 4 & & 96.5 & 21.5 \\
\hline
\end{tabular}

\section{Mathematical model}

Mathematical model was created using Matlab SimScape Fluids [5]. This model matches the experimental circuit.

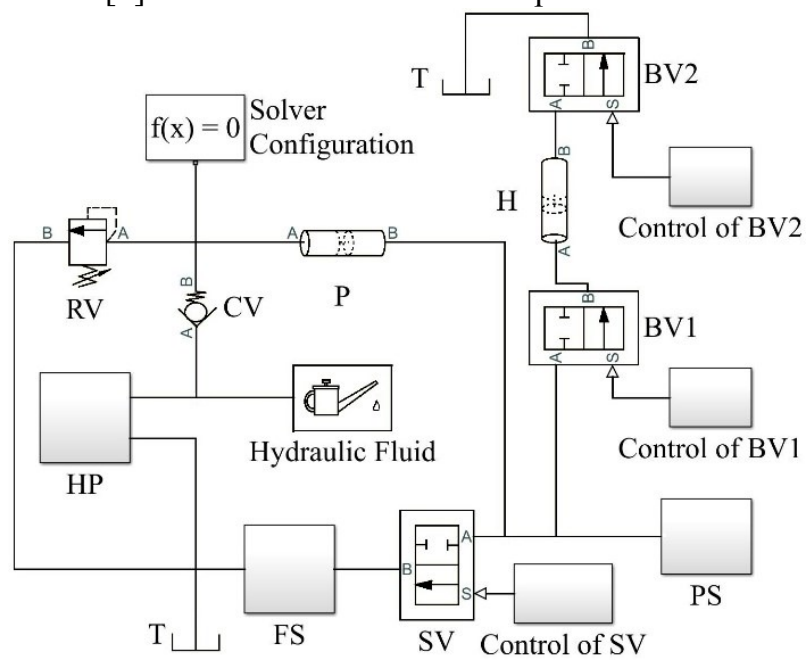

Fig. 4. Mathematical model of experimental circuit

The source of pressure energy is hydraulic pump HP. Check valve $\mathrm{CV}$ is located behind the pump and it protects pump HP. Relief valve RV is parallelly connected into pressure line. Relief valve RV is connected into tank T. Pressure line then continues into pipeline P. Seat valve SV is connected to pipeline $\mathrm{P}$ and its fast closing causes hydraulic shock. In front of the seat valve SV hydraulic hose $\mathrm{H}$ is parallelly connected and it represents the parallel capacitance. Connecting of the capacitance is controlled using ball valve BV1. Ball valve BV2 allows connection of hose $\mathrm{H}$ to tank $\mathrm{T}$. In front of the seat valve $\mathrm{SV}$, pressure sensor PS is located. Behind seat valve SV flow sensor FS is connected. Flow sensor FS is connected to tank T. Solver configuration and hydraulic fluid blocks are also connected to the circuit.

Block of segmented pipeline represents parallel connected hydraulic hose $\mathrm{H}$ in this model. Wall thickness is defined as flexible and this flexibility is defined by pressure - diameter coefficient $K_{H}$ [6]:

$$
K_{H}=\frac{d_{H}}{E_{H}} \cdot\left(\frac{D_{H}^{2}+d_{H}^{2}}{D_{H}^{2}-d_{H}^{2}}+v_{H}\right),
$$

where $d_{H}$ is inner diameter of hydraulic hose, $E_{H}$ is Young's modul of hydraulic hose, $D_{H}$ is outer diameter of hydraulic hose and $v_{H}$ is Poisson's ratio of hose material. Young's Modul of hydraulic hose is $E_{H}=5,9 \cdot 10^{9} \mathrm{MPa}$. Poisson's ratio of hose material is $v_{H}=0,47$ [7].

Block of segmented pipeline also represents pipeline $\mathrm{P}$ in this model. Wall thickness is defined as flexible and this flexibility is defined by pressure-diameter coefficient $K_{P}$ [6]:

$$
K_{P}=\frac{d_{P}}{E_{P}} \cdot\left(\frac{D_{P}^{2}+d_{P}^{2}}{D_{P}^{2}-d_{P}^{2}}+v_{P}\right),
$$

where $d_{P}$ is inner diameter of pipeline, $E_{P}$ is Young's modul of pipeline material, $D_{P}$ is outer diameter of pipeline and $v_{H}$ is Poisson's ratio of pipeline material. Pipeline is made from steel. Young's Modul of steel is $E_{H}=2,1 \cdot 10^{11} \mathrm{MPa}$. Poisson's ratio of steel is $v_{H}=0,3$ [7]. 
Oil bulk modulus is [6]:

$$
K=K_{0} \cdot \frac{1+\alpha \cdot\left(\frac{p_{a}}{p_{a}+p}\right)^{1 / n}}{1+\alpha \cdot K_{0} \cdot \frac{p_{a}^{1 / n}}{n \cdot\left(p_{a}+p\right)^{(n+1) / n}}},
$$

where $K_{0}$ is pure liquid bulk modulus, $\alpha$ is relative gas content at atmospheric pressure, $p_{a}$ is atmospheric pressure, $p$ is pressure, $n$ is gas - specific heat ratio.

Figure 5 simulates processes of pressure $p$ during hydraulic shock. Simulation took place for all hoses and without connected capacitance. Pressure peak is the highest without connected capacitance. The highest supression was caused by hose 1 .

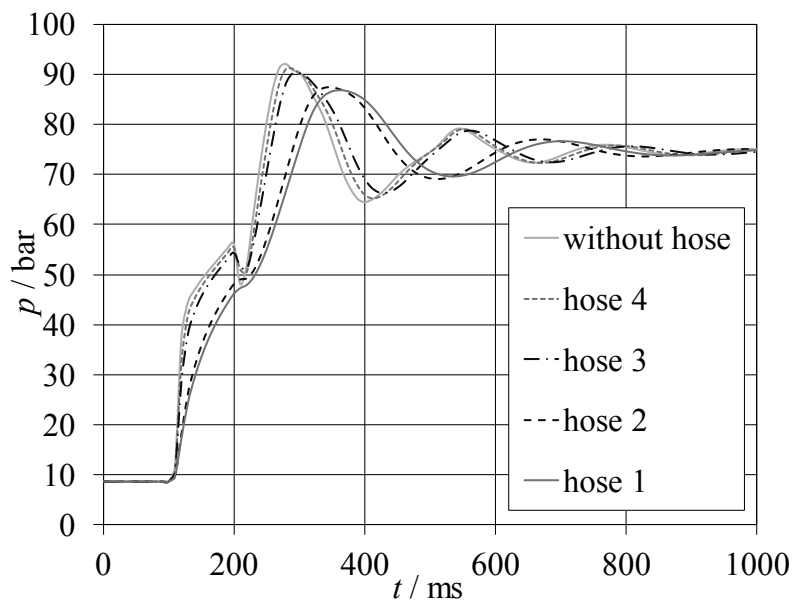

Fig. 5. Simulation of parallel capacitance influence

\section{Verification of mathematical model}

For verification of the mathematic model, mathematic simulation of hydraulic shock without connecting parallel capacitance and with hose 1 connected, was used. This hose was chosen because it has the highest capacitance and the decrease of pressure peak is the most significant. Graph in figure 6 shows a good match between the simulation and experimental measuring. The trend of the hydraulic shock process during the simulation is very similar to the experiment.

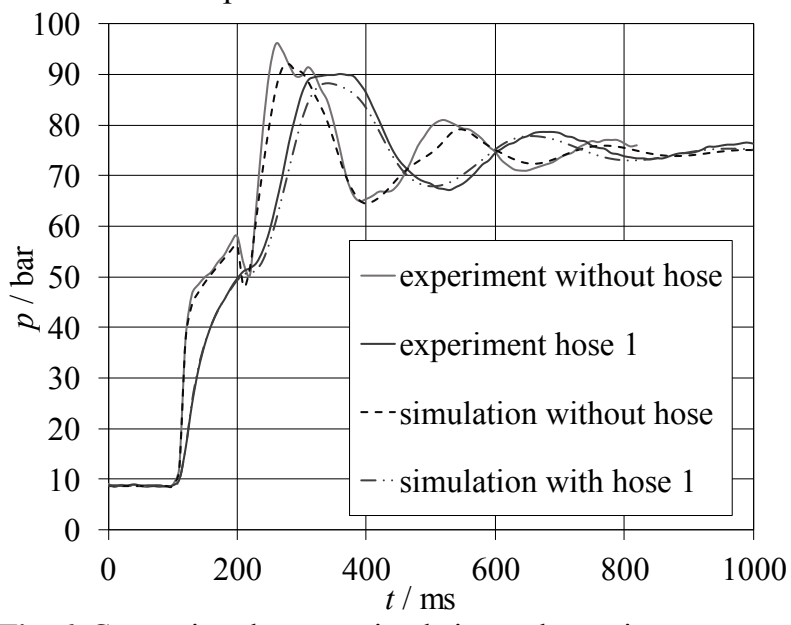

Fig. 6. Comparison between simulation and experiment

\section{Conclusion}

Measuring circuit was designed and assembled in order to determine the influence of parallel capacitance on the pressure response during hydraulic shock. It was started that particularly the inner diameter of the hose has significant influence on the lowering of pressure peak. The influence of the number of steel braids is less significant.

Furthermore a mathematical model of the experimental circuit was set up. The simulated time dependence of pressure $p$ matches the experimentally measured time dependence of pressure $p$.

This work was supported by the European Regional Development Fund in the Research Centre of Advanced Mechatronic Systems project, project number CZ.02.1.01/0.0/0.0/16_019/0000867 within the Operational Programme Research, Development and Education.

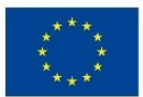

EUROPEAN UNION

European Structural and Investment Funds

Operational Programme Research,

Development and Education

The work presented in this paper was supported by a grant SGS „Modeling and Experimental Verification of Dynamic Phenomena in Fluid and Vacuum Systems" SP2018/157.

\section{References}

1. A. Bureček, L. Hružík, M. Vašina, Determination of Undissolved Air Content in Oil by Means of a Compression Method, Strojniski Vestnik - Journal of Mechanical Engineering, 61, No. 7-8, 477-485 p., (2015), DOI: $10.5545 /$ sv-jme.2015.2471

2. D. Himr, Investigation and Numerical Simulation of a Water Hammer with Column Separation, Journal of Hydraulic Engineering, 141, No. 3, 04014080, (2015) DOI: 10.1061/(ASCE)HY.1943-7900.0000967

3. J. Jablonská, EPJ Web of Conferences, EFM13, Compressibility of the fluid, 67, 02048, (2014), DOI: 10.1051/epjconf/20146702048

4. J. Mohieddine, A Kroll, Hydraulic Servo-systems, 51 p., 2003, ISBN 978-1-4471-1123-8

5. L. Hružík, A. Bureček, M. Vašina, EPJ Web of Conferences, EFM13, Non-stationary flow of hydraulic oil in long pipe, 67, 02042, (2014), DOI: 10.1051/epjconf/20146702042

6. The MathWorks, Matlab Simulink User's Guide, SimHydraulics User's Guide (USA, 2007)

7. N. D. Manring, Hydraulic control systems, 19 p., 2005, ISBN 978-0-471-69311-6. 